\title{
The Research on Willingness to Communicate in Chinese Students' EFL Study
}

\author{
$\mathrm{Li} \mathrm{Fu}$ \\ School of Foreign Languages, Harbin Institute of Technology, China \\ Xuesong Wang \\ School of Foreign Languages, Harbin Institute of Technology, China \\ Email:wangxs088@yahoo.com.cn \\ Yang Wang \\ School of Foreign Languages, Harbin Institute of Technology, China
}

\begin{abstract}
Willingness to communicate (WTC) has been a hot topic and focus all through these recent years in linguistics and EFL education in China. This paper makes a research on various factors that influence Chinese students' willingness to communicate in their EFL study. It also carries on an investigation on how WTC factors affect learners' class participation. The characteristics of Chinese students' WTC are also discussed. Lastly, the authors point out that EFL teachers should provide more opportunities for their students to experience success, create a good and safe learning environment and help learners to improve their WTC ability.
\end{abstract}

Index Terms - willingness to communicate, class participation, communication task, communication object, communication form

\section{INTRODUCTION}

Since 1950s, foreign language educators have gradually come to realize that the process of foreign language learning is not a simple learning process of language skills. Many WTC factors such as learning motivation, learning attitude, social support, and language environment affect this process. These views are held by many scholars like Wen \& Clement (2003), Yashima T. (2002) and Young, (1991). WTC, the new member in the family of the emotional factors, has gained a widespread attention in EFL field. Many people believe students' communicative ability is closely related to their willingness to communicate, and factors like conversational objects, communication tasks and communication forms also influence the intensity of willingness to communicate. The study of how WTC affect EFL learning has become a popular research in modern language teaching practices.

\section{WTC AND COMMUNICATION}

\section{A. Communicative Object}

Familiar communication object can enhance the students' WTC. Teachers should try to create a relaxing learning atmosphere for students. In EFL classes, students' self-introduction, or a wide range of questions may get students acquainted with each other and help demonstrate their language standard. As Hinkel found out that the WTC will be significantly higher when talking with friends and acquaintances than talking with teachers or strangers (1989). Conversational objects and the degree of familiarity, as McCroskey \& Richmond pointed out, also have a very profound impact on students' WTC (1990). Tomoko Yashima showed in his research that in terms of the number of people in a conversation, WTC is significantly higher when two persons are talking than that when several persons are talking (2002).Therefore, students should be allowed to select fixed communication objects in their classroom activities. In this way, students have higher initiative for classroom activities. Being familiar with the communicative objects, students may find they are willing to communicate with their fellow students in English, thus their practice opportunities increases. Meanwhile, Jiang Xin emphasized the support from teachers and other students also contribute to students' familiarity with their communication objects and help create a safe learning environment (2007).

\section{B. Communicative Task}

The authenticity and practicality of communication tasks are the successful keys to WTC. In other words, the selection of reading materials should be related to students' life. As Clement \& Mac Intyre point out, without the willingness to speak out, communication loses its foundation (2003). The appropriate selection of communicative topics is a prerequisite and guarantee for an effective communication. If students understand and have some relevant knowledge on a communicative task, their desire to express themselves will be inspired. Designs of some useful and 
interesting topics for students will stimulate students' talks. For students who have an intention to go abroad, the communicative tasks like exoticism, cultural conventions and application for admission are more welcome and more likely to motivate the students' class participation. Therefore, we get a conclusion that the familiarity with the discussion topics will promote the smooth progress in communication activities and increase students' WTC abilities.

\section{Communicative Form}

Foreign language learning should be carried out in authentic situations. MacIntyre \& Clement claim that students should learn in the real communication, make use of class activities, such as scenario simulations, games, role plays, to help them express creatively and freely (1999). In EFL teaching practices, teachers should design a variety activities centered on students' life and create a relaxing learning atmosphere to help students to express themselves. By pointing out the students' language mistakes, teachers can make students to express themselves in a comparatively coherent language.

Teaching software and a variety of audio and video equipments provide extra means in foreign language teaching. Vivid courseware can stimulate students' learning interest and enable teachers to grasp students' attention and get the timely feedback from them. McCroskey \& Baer suggested that the variety of communication forms and teaching modes can enable students' initiative and exploit their enthusiasm, increase their sense of class participation and enhance their willingness to communicate. As a consequence, the effect of learning will be improved (1985).

\section{WTC AND ClASS PARTICIPATION}

Class participation constitutes the most important part in EFL study. Many researchers and teachers have noticed that the most direct manifestation of students WTC lies in the students' active participation in classroom. There are many factors that affect the degree of students' classroom participation. In this paper, the authors also make their empirical investigation on how WTC affects students' class participation in their EFL classes.

\section{A. Problem Settings}

This research is to answer:1) the relationship between WTC and communication 2) How WTC factors affect class participation.

\section{B. Research Methodology and Procedure}

\section{Subjects}

The subjects participated in this study are students of non-English major in Harbin Institute of Technology, a total of 100. Among them, 80 boys, 20 girls, all aged between 20 to 22. Until now, they have learnt College English for one year in different majors, and all have 6 to 8 years of experience in English language study before entering university.

\section{Survey tools}

This research adopted 0xford Language Learning Strategies Inventory (1990) as a research tool. Due to the specific situation of Chinese students, some changes are made in this survey. This inventory is composed of 30 items. All responses to the items were made on a five-point Likert scale ( $1=$ totally inconsistent, $2=$ partly inconsistent; $3=$ totally consistent, 4=partly consistent and 5= always consistent). The authors conducted a questionnaire survey among 100 students in Harbin Institute of Technology, and the investigation covers five main factors in WTC: motivation, character, confidence, interest and culture. The results have been analyzed and studied through SPSS statistical analysis software.

\section{Data Collection}

Data collection was undertaken by questionnaire. A questionnaire survey was conducted among the subjects with the permission. Several steps were taken to ensure that the data collected from the questionnaire are valid and reliable. First, the participants were informed that any information they gave would be recorded anonymously and be kept confidential. Second, the students were told that they could ask any questions if they had troubles in understanding the questionnaire items. The number of valid questionnaires collected is 100 .

4. Data and Empirical Analysis

After the questionnaires had been withdrawn, the received data have been analyzed to conduct a reliable testing. We have figured out an average of all items. All the variables covered to conduct descriptive statistics, Mean and Std. Deviation and variables have been calculated and analyzed. The results are shown in Table 1: 


\begin{tabular}{|c|c|c|c|}
\hline \multicolumn{4}{|c|}{ TABLE 1} \\
\hline Number & MEAN & Std. Deviation & Variables \\
\hline 1 & 3.3 & 1.252 & 1.568 \\
\hline 2 & 2.3 & 1.252 & 1.568 \\
\hline 3 & 3 & 0 & 0 \\
\hline 4 & 3.5 & 0.707 & 0.5 \\
\hline 5 & 2.9 & 0.994 & 0.988 \\
\hline 6 & 3 & 1.764 & 3.112 \\
\hline 7 & 2.3 & 1.252 & 1.568 \\
\hline 8 & 1.8 & 1.317 & 1.734 \\
\hline 9 & 3.6 & 1.35 & 1.823 \\
\hline 10 & 2.7 & 1.494 & 2.232 \\
\hline 11 & 2.5 & 0.972 & 0.945 \\
\hline 12 & 4.5 & 0.527 & 0.278 \\
\hline 13 & 4.3 & 1.059 & 1.121 \\
\hline 14 & 2.9 & 1.37 & 1.877 \\
\hline 15 & 3.5 & 1.269 & 1.61 \\
\hline 16 & 2.7 & 1.059 & 1.121 \\
\hline 17 & 2.5 & 1.509 & 2.277 \\
\hline 18 & 3.6 & 1.506 & 2.268 \\
\hline 19 & 3.9 & 1.101 & 1.212 \\
\hline 20 & 2.4 & 1.506 & 2.268 \\
\hline 21 & 4 & 1.054 & 1.111 \\
\hline 22 & 2.4 & 1.35 & 1.823 \\
\hline 23 & 2.5 & 1.179 & 1.39 \\
\hline 24 & 2.3 & 1.494 & 2.232 \\
\hline 25 & 3.7 & 1.16 & 1.346 \\
\hline 26 & 2.8 & 1.135 & 1.288 \\
\hline 27 & 3.5 & 1.581 & 2.5 \\
\hline 28 & 2.6 & 1.43 & 2.045 \\
\hline 29 & 2.8 & 1.687 & 2.846 \\
\hline 30 & 1.6 & 0.843 & 0.711 \\
\hline
\end{tabular}

TABLE 2

TABLE 2 GIVES A VISUAL IMPRESSION OF WTC FACTORS THAT INFLUENCE CLASS PARTICIPATION.

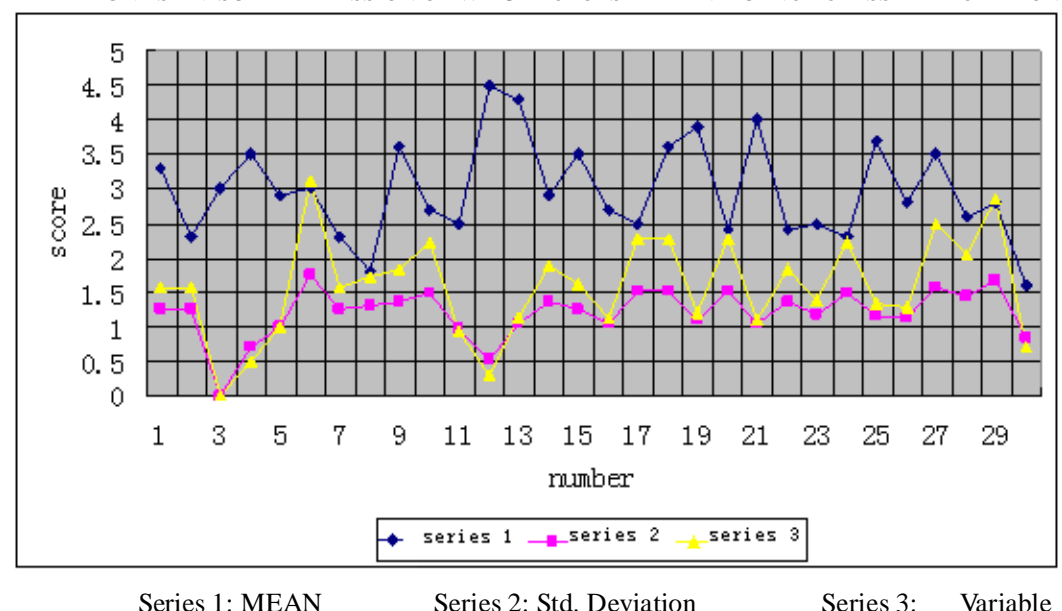

\section{Descriptive Statistics}

The means, standard deviations and variables for the scales of motivation, personality factors, self-confidence, interest and traditional culture are presented in Table1.

It is clear from the table that intensity in motivation $(M=3.3,3.5$ and 3) affects the students' participation level in classroom. The students with strong internal motivation have stronger sense of participation and more positive attitude. They are more eager to use the opportunities to communicate in class and can take the initiative to communicate. have better cooperation with their teachers and their English is better. Not much difference was found in Std. Deviations and variables.

Personality factors $(\mathrm{M}=3,2.3,1.8,3.6)$. As is displayed, the participants with extroverted character hold positive attitude in their study. They demonstrate strong self-confidence, and their performance in class is active and sociable; 
while introverts indicate lack confidence in their study, they take less initiative in class participation.

Confidence $(\mathrm{M}=4.5,4.3,2.9,3.5)$. We can see from Table 1 that the students with strong self-confidence perform actively in class discussions. They have good control over their learning.

Interest $(M=3.6,3,9$ and 4$)$ indicates that when the students' needs are satisfied, their desire to participate in class activities are more intense.

Last, traditional culture $(\mathrm{M}=2.7,2.4,2.3)$. Statistics suggests that the traditional Chinese culture has inhibited unconsciously the Chinese students' WTC in class participation.

\section{Analysis and Discussion}

\section{Motivation}

Motivation consists of two factors: need and stimulation. Some motivation is caused by the body's own needs. The other motivation is the stimulation by external things. Based on our survey, we divide our subjects into three categories:

The first type is students with external motivation; the second is students with mixed motives, that is, students not only have internal motivation, but also have external motivation. The third type is students with no motivation. The investigation find out that students with internal motivation have stronger sense of participation than those without. Their attitude is more positive and they are more eager for the communicative opportunities in class. Students with strong internal motivation are more willing to take the initiative to communicate and their English is better. A well-organized class setting is likely to help promote students' motivation. Students with mixed motives have more enthusiasm in class participation than those with external motivation, and they focus their attention on class participation better. When coming to cooperate with teachers, students with mixed motives have a better performance than those only with external motivation. Therefore, teachers should try to create an favorable learning environment to help and promote motivations of various learners' and increase learners' class participation.

The study also found that female students have stronger motivation to speak English than their male peers in class. Female learners have higher self-evaluation and hold more positive attitudes towards speaking English both in and after class. We also find out that freshmen have better motivation to speak English in class compared with the sophomores. Freshman' anxiety is lower. They hold an positive attitude towards speaking English.

\section{Character}

Different cultures pass different judgments on introversion and extroversion. In western countries, extroverted personality is more popular. While in the eastern countries, especially in China, less talk and more thought is considered a good character. In class participation, the extroverted students have stronger sense of participation, and are willing to talk, so they get more opportunities to practice what they learn. During the learning process, students with extroverted character will hold positive attitude, strong self-confidence. They get more language input and communication opportunities in class owing to their characteristic traits. They perform positively in class, like they love to ask questions, speak out without too much concern about "losing their faces" in public. They can absorb what they've learned through extensive try and practice. Extroverted learners are good at communication. The more they feel relaxed, the better they learn. Introverted learners, on the other hand, are quiet and shy and lack of confidence in their study and class participation. In class participation, introverted students are more often silent and stiff, and sometimes are nervous with blush. They are easier to get anxious when coming to answering questions. They will concern more about the impact they make on others in class participation. They are rarely speak even if they have some questions. They are not willing to raise their questions for fear of kidding. The fear of making mistakes and feeling awkward in class participation lead to their anxieties. As a result they have less chances to try and practise what they learn in classes and their language skills are relatively weak. "Silence is golden" and "Least said" and "the fear of losing face",--these traditional Chinese mode of thinking which are deeply rooted in many Chinese people hinder students' class participation, especially students with introverted characteristics.

As EFL teachers, we should understand the difference in students' character traits and adjust our teaching to satisfy different learners. We should motivate our students to their extremes.

\section{Self-confidence}

As we know, people with strong sense of self-confidence can face difficulties and have the courage and determination to overcome difficulties. In EFL classes, students with self-confidence are willing to pick up challenging objectives and believe that through their unremitting efforts they can successfully get these tasks done. While students with weak self-confidence tend to underestimate their abilities, take to tasks impersistently, and even think of giving up if these tasks are complicated.

As we find out in our research, students with strong self-confidence often grasp the nettle, and show initiative in class discussions; and students with less self-confidence tend to perform a fear of hardship and hold a passive attitude. Confident students also have good control in their own studies, have a sense of competence and easily achieve accomplishment in class; students with less self-confidence fear to speak English in front of the whole class. As they explain, facing so many classmates, they fear they can not find the appropriate words to express their ideas and worry about other students' ridicule. Rather than to face the "possible" embarrassment, these students would choose to keep silent during most of class time. These students' self-confidence to a large extent has influenced the degree of their class participation. Therefore, in EFL classes, teachers should strive to create a harmonious environment of "psychological security" and "psychological freedom", so as to reduce the anxieties among students and help to enhance their 
confidence to integrate into communicative activities in classes.

\section{Interests:}

Interest constitutes another important factor that affects class participation. When people are interested in something, the chances to get this thing done is comparatively greater. Abilities and interest will have mutual influence, and people with great interest in one area will often show strong ability in that field. This is also demonstrated in students' learning process. Students are interested in a particular subject, in all likelihood they will achieve better performance there. Due to their strong interest, students might take the initiative to read books on this subject and participate actively in class activities to get more information. When their needs are satisfied, their desire to participate in other class activities will become more intense and thus form a good cycling. In the end they make their success.

\section{Traditional culture:}

Chinese culture emphasizes collectivism and groups, underrates individualistic heroism. Chinese culture forms a set of philosophy of life as modesty, moderation, being worldly-wise and playing safe. Chinese collective view plays a vital role in inter-relations with the outside world. In EFL classes, collectivism is mainly reflected in "saving face" or maintain the dignity". Students are very concerned about others' assessment, so in order to avoid making mistakes in public, they often choose to remain silent. As EFL teachers find out an interesting phenomenon in their researches: in spite of the passive class participation among Chinese EFL learners, $80 \%$ of EFL students expressed their unwillingness to take the initiative to speak in class, and $85 \%$ of the students expressed their hope that everyone should has equal opportunity to speak. In the authors' opinion, this phenomenon can be explained as follows: Due to collectiveness is highly valued in Chinese culture, students do not want to "talk endlessly" in class activities. In Chinese cultures, "talk fluently and endlessly" and "speak volubly" will give people the image of ill-mannered. "Silence is golden" and "Least says," are the code of good conduct deeply rooted in the Chinese people. Therefore, some students advocate that in class they should not speak often, especially when the others are silent; If they talk a lot in classes, others classmates will consider them as showing offs. Most often Chinese students do not want to be special. As a result of fearing out of their group, they always choose to "follow the general trend"---remain silent in classes. At the same time, their strong motivation to learn among all things requires they have a good command of practical language skills. Therefore, EFL learners require their teachers to give them equal opportunities to speak out in classes.

When other factors for passive class participation are studied, traditional Chinese cultures influences such as being implicit, reserved, polite can not be neglected. Obviously, the cultural thought patterns hidden in Chinese students' subconsciousness have a recessive but decisive impact on their EFL class participation. We believe in the level of students' WTC in class will directly affect the cultivation of their communicative ability. Therefore, how to motivate Chinese students' WTC and enhance their communicative capability have naturally become our research project in our EFL teaching practices.

\section{OTHER FACTORS RELATED TO WTC}

Another factor that leads to weak WTC in class participation is the eagerness for quick success and instant benefits. Currently most EFL learners are very practical .Many university students are tired out by struggling to cope with a variety of English language exams. Many EFL classes naturally become places for mechanical drills (to meet the demand for exams) instead of language skills. EFL learners primarily focus their attentions on the analysis of grammar, recite new words, doing test papers, etc. Learners' purposes are to get high scores and certificates. There is no doubt that this certificate-oriented foreign language learning have a direct impact on students' class participation activities. Students are not interested in the real situational practices and believe these practices are sort of wasting their precious time in classes. Students would prefer EFL teachers teach them "useful strategies" such as how to guess in exams to help them achieve high scores. It can be seen that Chinese students' lack of WTC in EFL classes, to a certain degree, reflects the impact of current EFL education in China.

Shi Yunzhang found many students believe the lack of linguistic knowledge may hinder their WTC. Very often, they need to translate Chinese into English in their mind before speaking out (2008). This study confirms the anxieties many students have when they speak English or when they are asked to express off the cuff. In addition, many students' risk-taking in EFL classes is relatively low. When students are not quite sure about some words, grammar or expressions, they will first consult the dictionary, or resort to textbooks. If they assume that they might make mistakes, they would rather remain silent in classes. Finally, the learners' attitudes towards EFL study, classroom teaching and class participation all have influences on their WTC. Wang Chuming"s research shows some students believe they learn less knowledge in class activities. They still prefer the traditional teacher-oriented style (1990). However, all students agree that the boring classroom atmosphere has suppressed their WTC.

Rod pointed out that group cohesiveness is another important factor that affects the communicative competence. (1985). In a friendly and cohesive group, students are more willing to participate. Teachers' support also plays an important role. As MacIntyre \& Clement put it, teachers' linguistic and non-linguistic support has been proved to help promote the students' enthusiasm in class participation (1998). The forms of classroom organization, including teaching styles, the use of the teaching materials and the design of learning tasks, etc, will all influence the students' WTC. Since the traditional lecture modes (teacher-oriented) has been deeply rooted in Chinese learners' minds, students are not accustomed to carrying out their discussions independently or participating in interactive communication in EFL class. 


\section{CONCLUSION}

The research shows that EFL learners' WTC is closely related to the conversational objects, communicative tasks and communication form. It also relates closely to the factors like personal motivation, confidence, personality, interests and culture.

Therefore, in teaching practices, EFL teachers should try their best to enable their students to experience success, help them to enhance self-confidence, reduce anxiety and improve their WTC in foreign language study; it is also strongly advised that more authenticity in EFL classrooms be created and the students' autonomy be highlighted. In this way, the students could be in their best state of mood and study, which, just as Yu Weihua and Lin Minghong said, will definitely contribute to their learning outcomes (2004).

In a word, this empirical study intend to get EFL teachers to know more about their students' WTC in EFL learning process. We do hope that our analyses and the effective measures we put forward to improve EFL learners' communicative competence will work in their EFL study. We also hope that this research will contribute a little bit to the foreign language curriculum design, EFL textbook writing and College English teaching reform.

\section{REFERENCES}

[1] Clement, R., Baker, S. C., \& Mac Intyre, P.D. (2003).Willingness to communicate in a second language: The effects of context, norms and vitality. Journal of Language and Social Psychology. 22 (2) : 190 - 209.

[2] Eli Hinkel. (1989). Culture in Second Language Teaching and Learning. Cambridge: Cambridge University Press.

[3] McCroskey J. C. \& Baer J. E. (1985). Willingness to communicate: The construct and its measurement. Paper presented at the APACLSP.

[4] McCroskey J. C \& Richmond V. P. (1990). Willingness to communicate: Differing cultural perspectives. Southern Communication Journal. 56, $72-77$.

[5] MacIntyre P. D., Clement. R. (1998). Conceptualizing willingness to communicate in a L2: A situational model of L2 confidence and affiliation. The Modern Language Journal. 82.545-562.

[6] MacIntyre P. D., Babin P. A. \& Clement, R. (1999). Willingness to communicate: Antecedents and consequences. Communication Quarterly. 47. 215-229.

[7] Rod Eillis. (1985).Understanding Second Language Acquisition. Oxford: Oxford University Press.

[8] Tomoko Yashima. (2002).Willingness to Communicate in a Second Language: The Japanese EFL Context. The Modern Language Journal. Vol. 86. No. 1, 45.

[9] Wen W. P. \& ClementR. (2003). A Chinese conceptualization of willingness to communicate in ESL. Language, Culture and Curriculum. 16. 18-38.

[10] Yashima T. (2002). Willingness to communicate in a second language: The Japanese EFL context. The Modern Language Journal.86. 54-66.

[11] Young, Dolly J. (1991). Creating a Low Anxiety Classroom Environment: What Does Language Anxiety Research Suggest?. The Modern Language Journal. Vol. 76. 426- 437

[12] Jiang Xin. (2007). Psychological Exploration on foreign language teaching. Beijing: Educational Science Publishing House.

[13] Shi Yunzhang. (2008). Gender Differences in EFL reading anxiety and their relationship with Scores in Band 4 examination. Foreign Languages in China, (2), 96-97.

[14] Wang Chuming. (1990). Applied Psycholinguistics. Changsha, Hunan Education Publishing House.

[15] Yu Weihua, Lin Minghong. (2004).A Comparative Study on Willingness to Communicate between Guangzhou and Hong Kong University Students. Foreign Language Teaching and Research.(3),85.

Li Fu is a professor in Harbin Institute of Technology, China. Her main interest of research is applied linguistics and EFL teaching. She has been engaged in teaching English for more than twenty years.

Xuesong Wang is currently an associate professor in Harbin Institute of Technology, China. Her main interest of research is applied linguistics and EFL teaching. She has been engaged in teaching English for more than twenty years.

Yang Wang is a lecturer in Harbin Institute of Technology, China. Her main interest of research is applied linguistics and EFL teaching. She has been engaged in teaching English for ten years. 